\title{
Title: pancreatic-type mixed acinar neuroendocrine carcinoma of the stomach: a case report and review of the literature
}

\author{
Yuka Ooe 1* $^{*}$, Kishichiro Watanabe ${ }^{2}$, Isaya Hashimoto', Satoshi Takenaka ${ }^{3}$, Toshihiko Ojima',
} Seiichi Yamamoto ${ }^{1}$ and Hisatake Fujii ${ }^{1}$

\begin{abstract}
Background: The majority of gastrointestinal tumors are adenocarcinomas. Rarely, there are other types of tumors, such as acinar cell carcinoma, and these are often called pancreatic-type acinar cell carcinomas. Among these tumors, some are differentiated into neuroendocrine components. A few of them are MiNENs.

Case presentation: The patient was an 80-year-old male who was referred to our hospital for treatment of a pedunculated gastric tumor. It was $5 \mathrm{~cm}$ in diameter and detected in the upper gastric body with upper $\mathrm{Gl}$ endoscopy conducted to investigate anemia. In the biopsy, although hyperplasia of gastric gland cells was noted, no tumor cells were found. Retrospectively, the diagnosis was misdiagnosed. An operation was arranged because bleeding from the tumor was suspected as a cause of anemia and because surgical resection was considered to be desirable for accurate diagnosis. Hence, laparoscopic and endoscopic cooperative surgery was performed. In the pathological examination, several types of epithelial cells that proliferated in the area between the mucosa and deep inside the submucosa were observed. These consisted of acinar-glandular/trabecular patterns and solid. A diagnosis of pancreatic-type acinar cell carcinoma of the stomach with NET G2 and G3 was made based on characteristic cellular findings and the results of immunostaining tests. Each of them consisted of more than 30\% of the lesion; a diagnosis of pancreatic-type mixed acinar neuroendocrine carcinoma (pancreatic-type MiNEN) of the stomach or a type of gastric MiNEN was obtained. Anemia was resolved after the operation, and the patient was discharged from the hospital without perioperative complications.
\end{abstract}

Conclusions: Pancreatic-type ACC of the stomach that is differentiated into neuroendocrine tumors is very rare. Hence, we report this case along with a literature review.

Keywords: Gastric cancer, Acinar cell carcinoma, Neuroendocrine tumor, MiNEN, Laparoscopic surgery

\footnotetext{
* Correspondence: y.ooe0003@gmail.com

'Department of Surgery, Toyama Nishi General Hospital, 1019

Shimokutsuwada, Fuchumachi, Toyama, Toyama 939-2716, Japan

Full list of author information is available at the end of the article
}

C C The Author(s). 2021 Open Access This article is licensed under a Creative Commons Attribution 4.0 International License, which permits use, sharing, adaptation, distribution and reproduction in any medium or format, as long as you give appropriate credit to the original author(s) and the source, provide a link to the Creative Commons licence, and indicate if changes were made. The images or other third party material in this article are included in the article's Creative Commons licence, unless indicated otherwise in a credit line to the material. If material is not included in the article's Creative Commons licence and your intended use is not permitted by statutory regulation or exceeds the permitted use, you will need to obtain permission directly from the copyright holder. To view a copy of this licence, visit http://creativecommons.org/licenses/by/4.0/ The Creative Commons Public Domain Dedication waiver (http://creativecommons.org/publicdomain/zero/1.0/) applies to the data made available in this article, unless otherwise stated in a credit line to the data. 


\section{Background}

Acinar cell carcinoma (ACC) is a rare type of tumor that makes up 1-2\% of pancreatic tumors [1]. In 2002, Fukunaga [2] became the first to report a case of ACC that developed in the stomach. Since then, several cases of pancreatic-type acinar cell carcinoma of the stomach have been reported. The term "pancreatic-type acinar cell carcinoma", which Sun et al. [3] first used in a case of gastric cancer, has also been used for cancers of gastrointestinal and hepatobiliary locations other than the stomach.

In 2019, the WHO classification of neuroendocrine neoplasms was modified; mixed neuroendocrinenonneuroendocrine neoplasms (MiNENs) are mixed epithelial neoplasms in which a neuroendocrine component is combined with a nonneuroendocrine component, each of which is morphologically and immunohistochemically recognizable as a discrete component and constitutes > $30 \%$ of the neoplasm [4]. ACCs that develop in extrapancreatic tissues and MiNENs are so rare that their characteristics are not yet well understood.

We report here a case of pancreatic-type mixed acinar neuroendocrine carcinoma (pancreatic-type MiNEN) of the stomach (gastric MiNEN) with a literature review.

\section{Case presentation}

The patient was an 80-year-old male who had been followed up for hypertension and dyslipidemia. His height was $167 \mathrm{~cm}$, his weight was $69.7 \mathrm{~kg}$, and he had a surgical history of appendectomy for appendicitis. Anemia was observed in the conjunctiva. The abdomen was flat and soft without tenderness. There was a surgical scar from the appendectomy. No superficial lymph node was palpated.

In the blood test, the $\mathrm{Hb}$ level was 10.2, suggesting anemia. AMY at $66 \mathrm{IU} / \mathrm{L}$ was within the reference range, and no abnormality in other blood biochemistry tests was observed. Tumor marker levels were CEA $1.9 \mathrm{ng} /$ $\mathrm{mL}$ and CA19-9 13.6 U/mL, both within their reference ranges. A pedunculated gastric tumor was detected in the upper gastric body with upper gastrointestinal endoscopy (Fig. 1). Reddish changes, which may indicate epithelial tumors, were detected on the apex of the tumor. Ulcer formation was observed, and invasion to the submucosal tissues could not be ruled out. There was no obvious bleeding detected in this examination. A biopsy was performed, and histopathological malignancy was not revealed. A kind of gastric gland cell hyperplasia was diagnosed, probably because it seemed that no significant atypia was found in the specimen.

On abdominal/pelvic computed tomography (Fig. 2), a neoplastic lesion of $5 \mathrm{~cm}$ in diameter was observed in the upper gastric body. As it was located on the pyloric side of the upper gastric body, pyloric obstruction was

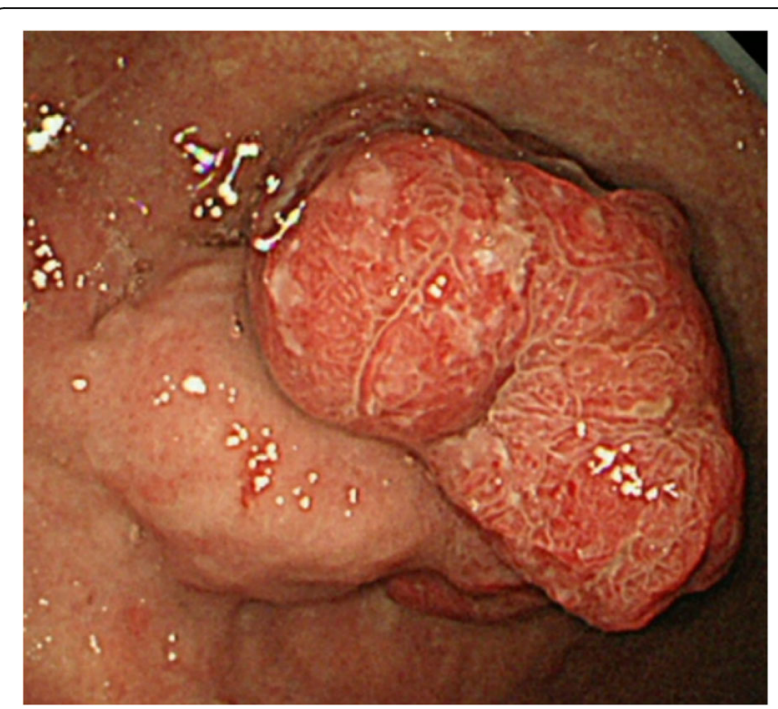

Fig. 1 Esophagogastroduodenoscopy findings. A large ulcerated fungated mass in the gastric upper body

also suspected. There was no finding suggesting a pancreatic tumor, lymphadenopathy, or metastatic lesions. No ascites was observed.

A surgical procedure was arranged for the following reasons: bleeding from the tumor was suspected as a cause of anemia, ball valve syndrome had been induced by the tumor, the possibility of malignancy could not be ruled out, and the risk of incomplete resection or bleeding with endoscopic resection was considered high.

Laparoscopic endoscopic cooperative surgery was performed. A tumor incarcerated from the greater curvature of the upper gastric body to the duodenum was guided into the gastric cavity under endoscopic observation. Full-thickness resection was performed while maintaining an approximately $10-\mathrm{mm}$ margin. The resected site was closed with layer-to-layer sutures.

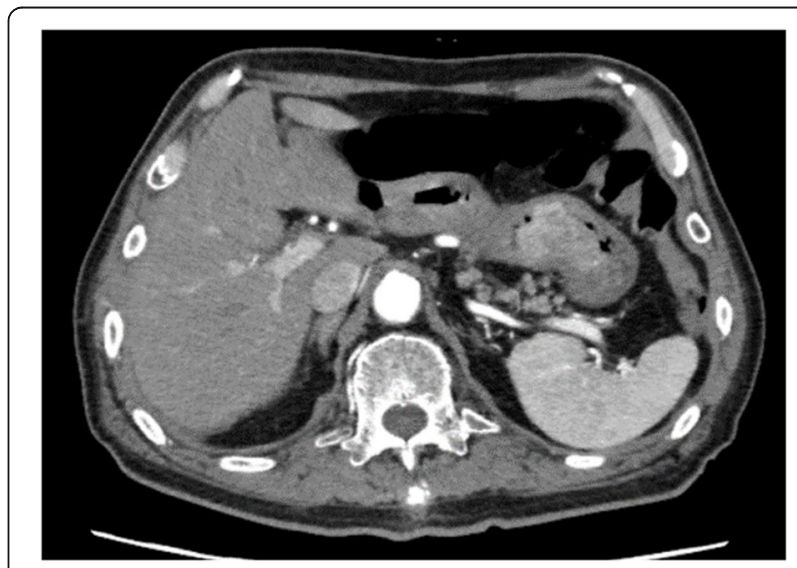

Fig. 2 Abdominal computed tomography. Enhanced gastric tumor incarcerated to the antrum 


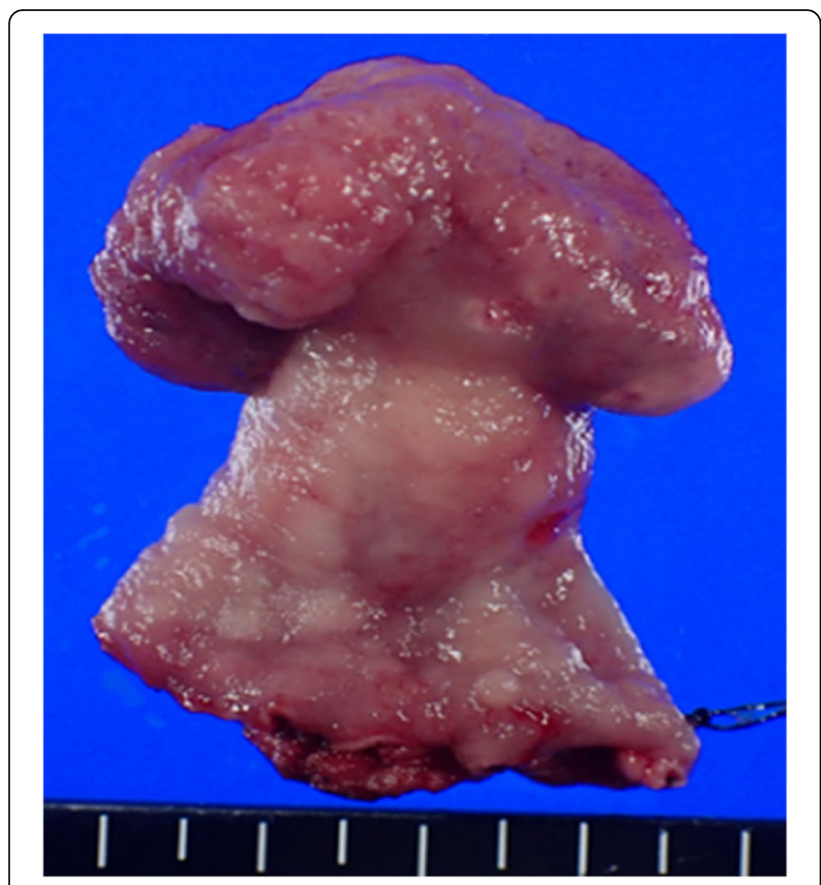

Fig. 3 Macroscopic findings

Macroscopically, an elastic-hard grayish-white solid neoplastic $3.5 \times 3.3 \times 2.5$ - $\mathrm{cm}$ lesion protruding inside the gastric cavity was observed. Some parts were edematous on the sectional surface, and no necrosis or bleeding was observed (Figs. 3, 4).

Whole-section slides from the resected tissues were made. Histologically, the lesion consisted of a remarkable proliferation of several types of epithelial cells in the mucosa and submucosa. The border of the lesion was very irregular in the mucosa or the superficial layer of the lesion; however, it was clear in the submucosa or middle and deep inside layer of the lesion with partial fibrosis and a capsule. The propria muscularis was not involved. Proliferating epithelial cells showed basically acinar-glandular, trabecular and solid patterns (Fig. 5). These patterns were seen separately in some parts and intermingled with one another in other parts. Small amounts of stromal mucus deposition were found in some parts of the superficial layer of the lesion. Regarding the general tendency, the solid pattern was found mainly in the mucosa or the superficial layer of the lesion, while the acinar-glandular and trabecular patterns were observed in the submucosa or deep inside of the lesion. Since the morphological atypia of these proliferative epithelial cells was not significant and these cells resembled pancreatic acinar cells well, the possibility of a special type of ectopic pancreas was considered first. However, normal pancreatic cells (e.g., acinar, ductal, islet cells) that support a diagnosis of heterotopic pancreas were not observed at all.

The cells that proliferated as acinar-glandular and trabecular patterns (Fig. 5a and b) contained eccentric nuclei, which appeared to be slightly enlarged, presenting conspicuous nucleoli, as well as eosinophilic granules inside the cells. The cells that proliferated as the solid pattern (Fig. 5c) had oval nuclei, presenting salt and pepper-like chromatin that was distributed heterogeneously and slightly eosinophilic granules inside the cells. Aggregations/mixtures of small cells and large cells were also observed on an image (Fig. 5d). Although significant atypical cells were rare for each type, the characteristics of the nuclei and nucleoli of the cells mentioned above and irregularity of the border of the lesion in the mucosa or the superficial layer led us to the idea that the lesion may be acinar cell carcinoma with some neuroendocrine features.

To confirm this idea, immunostaining was performed using various pancreas-related markers or neuroendocrine markers. Immunostaining tests revealed that most of the lesion was strongly positive for BCL-10 antibody (Fig. 6a) and trypsin but negative or weak in some small parts of the superficial layer of the lesion. In addition, strongly positive results were obtained for chromogranin A, synaptophysin, and CD56 neuroendocrine markers, especially in the superficial layer of the lesion, in which the negative or weak parts for BCL-10 and trypsin were
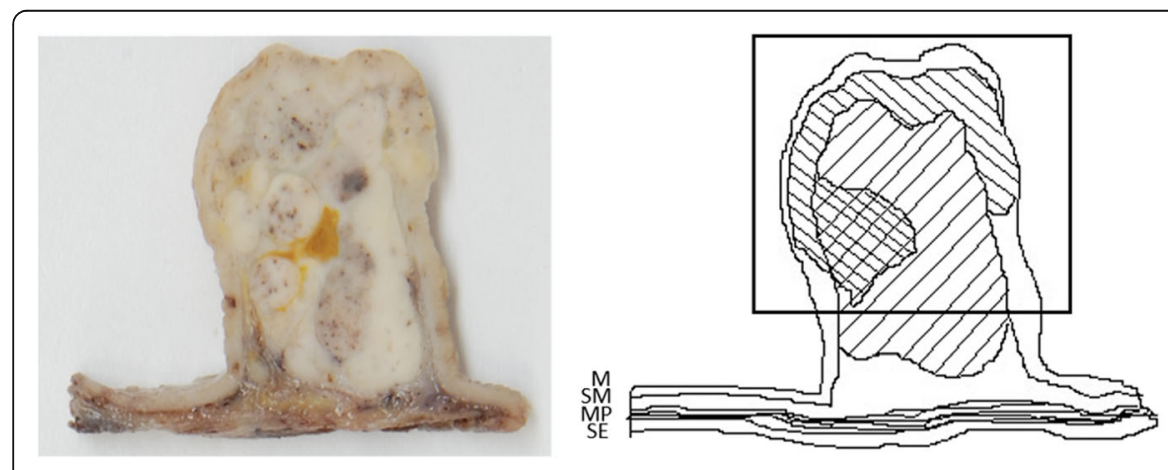

Solid pattern

Acinar-glandular and trabecular pattern

Amphicrine area

Fig. 4 Schematic diagram of each component. The square indicates the area shown in Fig. 6 


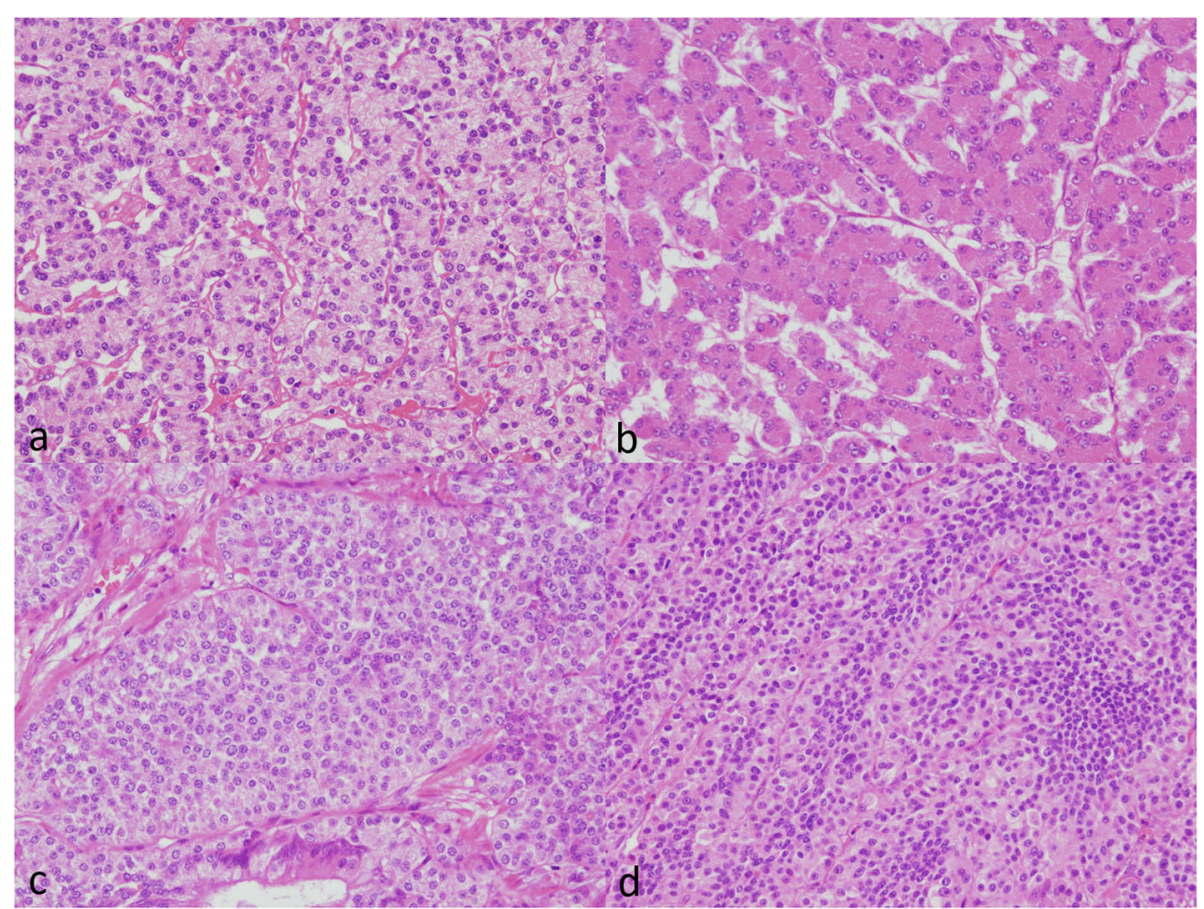

Fig. $5(\mathbf{a}, \mathbf{b}, \mathbf{c}, \mathbf{d})$ a: acinar-glandular pattern $\times 200$ b: trabecular pattern $\times 200$ c: solid pattern $\times 200$ d: solid pattern (large and small cells) $\times 200$

almost positive. Regarding neuroendocrine reactivity in this case, chromogranin A was most remarkable among the three neuroendocrine markers, suggesting that it accounted for $40 \%$ of the lesion (Fig. 6b). Concerning the mitotic rate and Ki-67 index of the lesion, the proportions of acinar-glandular and trabecular cells proliferating mainly in the submucosa or middle and inside of the lesion were $<2$ and $<3 \%$, respectively, while those of solid cells proliferating mostly in the mucosa or superficial layer of the lesion were mainly $2-5$ and $3-20 \%$, respectively. Moreover, in some small parts of the layer, the proportions were $>20$ and 20-40\%. Epithelial markers such as CK7, CK20, CAM5.2 and AE1/AE3 were positive in the entire lesion as well as in the existing gastric mucosal epithelium. CK19, which is a pancreatic ductal marker, showed positivity in some parts of the superficial layer of the lesion and the existing gastric mucosa but negativity in the middle or deep inside of the lesion.

Additionally, the tests for pancreatic and digestive tract-related hormones (e.g., insulin and gastrin) were negative. No intranuclear positive finding was observed with beta-catenin either. The immunostaining tests are presented in Table 1.

The nearest resected margin from the lesion was $0.5 \mathrm{~cm}$ and free from the tumor. No fundic gland was observed in the existing gastric mucosa. The mucosa consisted of crypt epithelium with intestinal
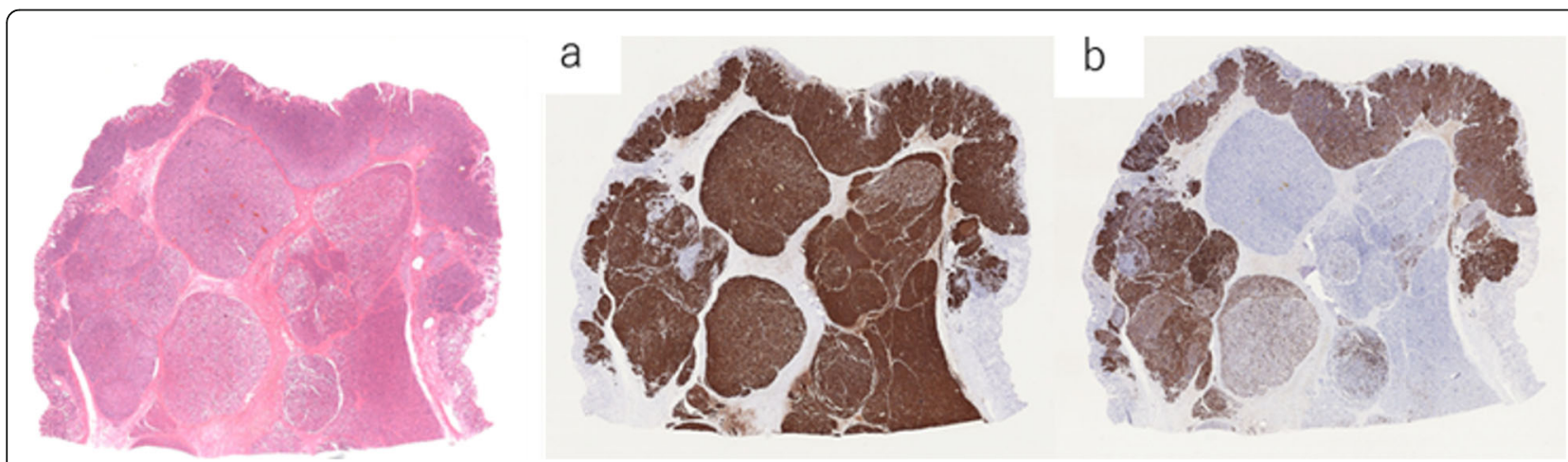

Fig. $6(\mathbf{a}, \mathbf{b})$ a: anti-BCL-10 antibody staining $\mathbf{b}$ : chromogranin A staining 
Table 1 Antibodies employed in the immunohistochemical study and results

\begin{tabular}{|c|c|c|c|c|c|c|}
\hline \multirow[b]{2}{*}{ Antibody } & \multicolumn{2}{|l|}{ Growth pattern } & \multirow[b]{2}{*}{$\begin{array}{l}\text { Overlying gastric } \\
\text { mucosa }\end{array}$} & \multirow[b]{2}{*}{ Clone } & \multirow[b]{2}{*}{ Source } & \multirow[b]{2}{*}{ Dilution } \\
\hline & $\begin{array}{l}\text { Acinar-glandular } \\
\text { pattern }\end{array}$ & $\begin{array}{l}\text { Solid } \\
\text { pattern }\end{array}$ & & & & \\
\hline$\overline{B C L-10}$ & +++ & ++ & - & 331.3 & Santa Cruz Biotechnology & $1: 50$ \\
\hline Trypsin & +++ & ++ & - & & Merck Millipore & $1: 2000$ \\
\hline Chromogranin A & + & +++ & - & SP12 & Thermo Fisher Scientific & $1: 75$ \\
\hline Synaptophysin & + & ++ & - & SP11 & Thermo Fisher Scientific & $1: 75$ \\
\hline CD56 & + & ++ & - & & Nichirei Bioscience & prediluted \\
\hline Amylase & + & + & + & & & \\
\hline Insulin & - & - & - & & DakoCytomation & $1: 100$ \\
\hline Glucagon & - & - & - & & DakoCytomation & $1: 200$ \\
\hline Gastrin & - & - & - & & DakoCytomation & $1: 300$ \\
\hline Serotonin & - & - & - & & DakoCytomation & $1: 50$ \\
\hline Somatostatin & - & - & - & & Roche & prediluted \\
\hline $\begin{array}{l}\text { Pancreatic } \\
\text { polypeptide }\end{array}$ & - & - & - & & DakoCytomation & $1: 600$ \\
\hline$\beta$-catenin & \multicolumn{2}{|c|}{ + (cell membrane, cytoplasm) } & & & DakoCytomation & $1: 200$ \\
\hline CK7 & - & - & + & $\begin{array}{l}\text { OV-TL12/ } \\
30\end{array}$ & DakoCytomation & $1: 75$ \\
\hline CK19 & - & - & + & RCK108 & DakoCytomation & $1: 75$ \\
\hline CK20 & - & - & + & KS20.8 & DakoCytomation & $1: 75$ \\
\hline CAM5.2 & + & + & + & & $\begin{array}{l}\text { Becton, Dickinson and } \\
\text { Company }\end{array}$ & prediluted \\
\hline CKAE1/AE3 & + & + & + & & DakoCytomation & prediluted \\
\hline
\end{tabular}

metaplasia and hyperplasia, and no obvious malignancy was detected.

Regarding the tumor tissues presenting acinarglandular and trabecular patterns, a diagnosis of pancreatic-type acinar cell carcinoma of the stomach was made according to the characteristic findings, such as clear and swollen nucleoli and the results of immunostaining tests. Most of the tumor tissue that presented a solid pattern showed neuroendocrine tumor (NET) G2 characteristics as well as acinar cell carcinoma. However, some parts of that area showed the characteristics of NETG3 without those of ACC.

Considering that each component accounted for more than $30 \%$ and that both of them had been mixed and shifted with each other, a diagnosis of pancreatic-type mixed acinar neuroendocrine carcinoma (pancreatic-type MiNEN) of the stomach (gastric MiNEN) was made.

Postoperative course: No perioperative complications were observed; the patient started consuming meals on day 3 after the operation, and on day 13, he was discharged from the hospital. In the blood test, the Hb level had increased to 14.1, suggesting that his anemia had been resolved. Unfortunately, the patient died of brainstem hemorrhage 4 months after the operation. No autopsy was performed.

\section{Discussion}

In 2002, Fukunaga [2] became the first to report a case of acinar cell carcinoma that developed in the stomach. Since then, a total of 13 cases of gastric ACCs (including ACCs that also contain neuroendocrine tumor cells) have been reported [3,5-12]. In addition, there are other reports of ACCs in the duodenum, papilla, small intestine and liver; ACCs that develop outside the pancreas are often called pancreatic-type ACCs [13-17].

Rarely, some gastrointestinal tumors demonstrate both exocrine and neuroendocrine differentiation. According to the World Health Organization (WHO) 2010 classification [18], this group of tumors are called mixed adenoneuroendocrine carcinomas (MANECs), and in the 2017-2019 WHO classification [4, 19], these tumors were renamed mixed neuroendocrine-nonneuroendocrine neoplasms (MiNENs). Recently, La Rosa et al. [20, 21] advocated a detailed classification (Table 2).

It is difficult to obtain a diagnosis of pancreatic-type ACCs of the stomach with endoscopic biopsy [11], and it seems even more difficult to diagnose MiNENs 
Table 2 Classification of MiNEN according to their grade of malignancy

\begin{tabular}{|c|c|c|}
\hline & Non-neuroendocrine component & Neuroendocrine component \\
\hline High-grade MiNEN & Carcinoma ${ }^{a}$ or adenoma & $\begin{array}{l}\text { Poorly differentiated neuroendocrine carcinoma (G3) of small- } \\
\text { or large-cell type }\end{array}$ \\
\hline \multirow[t]{2}{*}{ Intermediate-grade MiNEN } & Carcinoma $^{a}$ & Well-differentiated neuroendocrine tumour (G1-G2) \\
\hline & Amphicrine carcinomas & \\
\hline Low-grade MiNEN & Adenoma & Well-differentiated neuroendocrine tumour (G1-G2) \\
\hline
\end{tabular}

Adapted from La Rosa et al [7]. a Carcinoma generally consists of adenocarcinoma but can be squamous-cell or acinar-cell carcinoma as well

because it seems that the terms and concepts of "pancreatic-type ACC", "pancreatic-type MiNENs" and "gastric MiNEN" are not widely understood and accepted. Chymotrypsin and amylase markers can be useful in these diagnoses [11]. It has been reported recently that immunostaining with anti-BCL-10 antibody can be a marker that is high in terms of both sensitivity and specificity for pancreatic acinar cells as well as for cells that present acinar cell differentiation [22]. For this patient, who had been diagnosed with gastric gland cell hyperplasia by endoscopic biopsy before the operation, the result of a postoperative immunostaining test was strongly positive for anti-BCL-10 and chromogranin A antibodies. Hence, immunostaining tests using anti-BCL-10 antibody and other markers can be useful and should be considered for preoperative diagnosis.

It has also been reported that $42 \%$ of ACCs of the pancreas would be positive for a neuroendocrine marker [8]. Therefore, there is some confusion between the diagnosis of acinar cell carcinoma and neuroendocrine carcinoma of the pancreas. In general, a solid pattern is morphologically considered to be one of the acinar cell carcinoma patterns of the pancreas [4]. However, it seems valid that the solid pattern in our case can be regarded as a morphologically recognizable discrete component, which is consistent with the definition of MiNEN.

Our case is very rare in that it was a type of gastric MiNEN that consisted of pancreatic-type ACC and neuroendocrine tumor that was a mixed acinar neuroendocrine carcinoma or pancreatic-type MiNEN of the stomach. In addition, a small amount of stromal mucus deposition and some CK19-positive cells were detected in the superficial layer of the lesion in our case. These findings suggest that our case might be related to mixed acinar neuroendocrine ductal carcinoma.

To the best of our knowledge, 13 cases of gastric ACCs and gastric MiNENs accompanied by pancreatic acinar cell differentiation have been reported [2, 3, 512] (Table 3). Regarding the onset mechanism, it was considered that they developed from the ectopic pancreas and had been called "pancreatic-type ACC of the stomach" in some reports. Of these, ectopic pancreas was detected histologically in only one case [7]. In other cases, it was considered that the ectopic pancreas might have been destroyed and vanished due to tumor proliferation. Gastric MiNENs usually consist of welldifferentiated adenocarcinoma and neuroendocrine carcinoma (NEC) components [23], and there is a tendency in the conditions of their distributions, namely, that the latter component often exists deep inside the lesion and the former in the surface of the lesion [24]. Regarding the onset mechanism of MiNENs (MANECs), Makuuchi et al. [24] proposed that during the process in which adenocarcinoma, which originally develops within the mucosa, invades deep inside the lesion, neoplastic endocrine cells that have higher proliferation potency would grow; hence, NEC is observed following MANEC. However, an opposite tendency was observed in the present case. In other words, neuroendocrine tumors existed on the surface of the lesion, and the ACC was located deep inside the lesion. As an ectopic pancreas is commonly detected in the submucosa [25], it can be considered that these distributions may support the idea that they develop from an ectopic pancreas. Regarding the site of onset, an ectopic pancreas in general is likely to develop on the pyloric side [26]. However, in previous reports, it developed in various sites other than the pyloric side, such as near the cardiac orifice or in the upper gastric body. In the present case, it also developed in the upper gastric body. Metastasis of tumors from other organs, such as the pancreas, could be ruled out for this patient, as there was no significant finding on imaging that indicated a primary lesion in this case. Hence, we consider the following 3 conditions, other than development from the ectopic pancreas, as the onset mechanism of this tumor: 1. A tumor that simultaneously contains two distinctive cellular components develops, 2. A tumor that contains two components originating from a pluripotent stem cell with the potential for divergent differentiation, and 3. A condition in which part of the nonneuroendocrine tumor is turned into a neuroendocrine tumor or in which part of the neuroendocrine tumor is turned into a non-neuroendocrine tumor. The immunostaining study with the most surface layer of the lesion indicating a neuroendocrine neoplasm revealed partial positive BCL-10 staining. That may suggest the third condition. 
Table 3 List of carcinomas with pancreatic acinar cell differentiation reported in the literature

\begin{tabular}{|c|c|c|c|c|c|c|c|c|c|}
\hline Author, year & Age & Sex & Site & Diagnosis & Metastasis & $\begin{array}{l}\text { Ectopic } \\
\text { pancreas }\end{array}$ & Therapeutic option & Adjuvant therapy & Outcome \\
\hline Fukunaga, 2002 [2] & 77 & $\mathrm{~F}$ & Fundus & MAEC & None & None & EMR & - & Alive, $7 \mathrm{mo}$ \\
\hline Sun et al., 2004 [3] & 86 & $F$ & Antrum & ACC & None & None & partial gastrectomy & - & NM \\
\hline \multirow[t]{3}{*}{ Jain et al., 2005 [5] } & 41 & $\mathrm{~F}$ & Body & MAEC & LN & None & $\begin{array}{l}\text { partial gastrectomy, } \\
\text { partial omentectomy }\end{array}$ & - & Alive, $2 \mathrm{yr}$ \\
\hline & 61 & M & Fundus & MAEC & LN, Liver & None & subtotal gastrectomy & - & Dead, 6mo \\
\hline & 72 & M & Body & MAEC & None & None & subtotal gastrectomy & - & Dead, 4mo \\
\hline Mizuno et al., 2007 [6] & 73 & M & Pylorus & $N A^{a}$ & LN, Liver & None & pancreaticoduodenectomy & $\begin{array}{l}\text { Gemcitabine+ } \\
\text { Cisplatin+ 5-FU }\end{array}$ & Alive, $11 \mathrm{mo}$ \\
\hline $\begin{array}{l}\text { Ambrosini-Spaltro } \\
\text { et al., } 2009 \text { [7] }\end{array}$ & 52 & M & Antrum & ACC & None & Presence & $\begin{array}{l}\text { subtotal gastrectomy, } \\
\text { omentectomy, } \\
\text { cholecystectomy }\end{array}$ & NM & NM \\
\hline $\begin{array}{l}\text { Kusafuka et al., } \\
2009 \text { [8] }\end{array}$ & 56 & $F$ & Body & MAEC & $\begin{array}{l}\text { Peritoneum, } \\
\text { Liver, Skin }\end{array}$ & None & $\begin{array}{l}\text { total gastrectomy, } \\
\text { splenectomy, right-half } \\
\text { colonectomy }\end{array}$ & S-1 + Cisplatin & Dead \\
\hline Coyne, 2012 [9] & 77 & $\mathrm{~F}$ & Fundus & ACC & None & None & partial gastrectomy & - & Dead, $1 \mathrm{mo}$ \\
\hline \multirow[t]{2}{*}{$\begin{array}{l}\text { Yonenaga et al., } \\
2016 \text { [10] }\end{array}$} & 67 & M & Body & MAEC & LN & None & $\begin{array}{l}\text { distal gastrectomy, } \\
\text { lymph node dissection }\end{array}$ & S-1 monotherapy & Alive, $21 \mathrm{mo}$ \\
\hline & 63 & M & Antrum & ACC & Liver & None & - & Gemcitabine+Erlotinib & Dead, $5 \mathrm{mo}$ \\
\hline Kim et al., 2017 [11] & 54 & M & Cardia & ACC & None & None & $\begin{array}{l}\text { laparoscopic wedge } \\
\text { resection }\end{array}$ & - & Alive, $33 \mathrm{mo}$ \\
\hline Fujita et al., 2019 [12] & 67 & M & NM & MiNEN & None & None & ESD & - & Alive, $15 \mathrm{mo}$ \\
\hline
\end{tabular}

NM not mentioned

ACC acinar cell carcinoma

MAEC mixed acinar endocrine carcinoma

MiNEN mixed neuroendocrine-non-neuroendocrine neoplasms

$E M R$ endoscopic mucosal resection

ESD endoscopic submucosal dissection

$L N$ lymph nodes

mo months

yr years

$N A^{a}$, the immunohistochemistry for neuroendocrine markers was not performed

Gastric MiNENs usually consist of adenocarcinoma and NEC components. In such a case, it is assumed that the latter component would determine the prognosis of MiNENs [27].

According to a report on pancreatic tumors, the prognosis of ACCs is better than that of ductal adenocarcinomas, which account for most pancreatic tumors. However, it is still challenging, as the median survival time is approximately 19 months and the 5 -year survival rate is approximately $25 \%$. Malignant findings such as significant atypical cells or frequent mitotic cells were rare in the present case. The effects of such morphological characteristics, the immunostaining test results, and molecular abnormalities on disease prognosis have been investigated in recent studies. However, only tumor staging has ever been verified as a factor associated with prognosis [28].

As there is no standard opinion for the treatment of gastric MiNENs, it is considered important to determine a treatment approach for each case according to the tumor components. A management approach for gastric ACCs has not yet been determined, as the number of cases is limited. However, surgical treatment should be the first option for localized pancreatic ACCs [29]. According to a report on 865 cases studied based on the National Clinical Database, satisfactory outcomes were achieved in the surgically treated group compared to the nonsurgically treated group; the five-year survival rates were $36.4 \%$ (median, 27 months) and $10.4 \%$ (median, 7.1 months), respectively. For unresectable or distant metastasis cases, chemotherapy or radiotherapy for downstaging purposes could be an option to downstage the disease to allow for surgical resection [30]. In the present case, the outcome was death due to brainstem hemorrhage. However, it was considered to be an accident, as the relationships between MiNEN, ACC, NET/NEC and cerebrovascular diseases are currently unknown. 


\section{Conclusion}

We experienced a case of pancreatic-type ACC of the stomach. A diagnosis of MiNEN was also made, as nearly $40 \%$ of the tumor cells had been differentiated into neuroendocrine tumor cells (pancreatic-type mixed acinar neuroendocrine carcinoma or pancreatic-type MiNEN). The number of reports on pancreatic-type ACCs or MiNENs has been increasing due to advanced immunological technologies. However, these are not yet well understood, as the number of cases is still very small. Further studies are required to clarify the characteristics of the tumor, to determine the treatment approach and to improve patient prognosis.

\section{Abbreviations}

ACC: Acinar cell carcinoma; MiNEN: Mixed neuroendocrinenonneuroendocrine neoplasms; NET: Neuroendocrine tumor; WHO: World Health Organization; MANEC: Mixed adenoneuroendocrine carcinoma; NEC: Neuroendocrine carcinoma

\section{Acknowledgments}

The authors would like to thank American Journal Experts (https://secure.aje. com/en/researcher/) for English language editing.

\section{Authors' contributions}

Y.O. is the first author and prepared the manuscript under the supervision of K.W., I.H., S.T., T.O., S.Y. and H.F. All authors approved the final version of the manuscript.

\section{Funding}

Not applicable.

\section{Availability of data and materials}

The dataset supporting the findings and conclusions of this case report is included within this article.

\section{Ethics approval and consent to participate}

Not applicable.

\section{Consent for publication}

Written informed consent was obtained from the patient for publication of this case report and any accompanying images.

\section{Competing interests}

The authors declare that they have no competing interests.

\section{Author details \\ ${ }^{1}$ Department of Surgery, Toyama Nishi General Hospital, 1019 Shimokutsuwada, Fuchumachi, Toyama, Toyama 939-2716, Japan. Watanabe's Consultancy for Pathological Diagnosis, 1007 Surpass Sakurada-cho Ichibankan 3-30-1 Sakurada-cho, Kanazawa, Ishikawa 920-0057, Japan. ${ }^{3}$ Department of Surgery, Suzu General Hospital, 1-1 Nonoemachi, Suzu, Ishikawa 927-1213, Japan.}

Received: 8 November 2020 Accepted: 21 January 2021 Published online: 02 February 2021

\section{References}

1. Hartman CG, Ni H, Pickleman J. Acinar cell carcinoma of the pancreas. Arch Pathol Lab Med. 2001:125:1127-8.

2. Fukunaga M. Gastric carcinoma resembling pancreatic mixed acinarendocrine carcinoma. Hum Pathol. 2002:33:569-73.

3. Sun $Y$, Wasserman PG. Acinar cell carcinoma arising in the stomach: a case report with literature review. Hum Pathol. 2004;35:263-5.

4. WHO Classification of Tumours Editorial Board. WHO classification of Tumours. Digestive system Tumours. 5th ed. Lyon: International Agency for Research on Cancer (IARC; 2019.
5. Jain D, Eslami-Varzaneh F, Takano A, Ayer U, Umashankar R, Muller R. Composite glandular and endocrine tumors of the stomach with pancreatic acinar differentiation. Am J Surg Pathol. 2005;29:1524-9.

6. Mizuno $Y$, Sumi $Y$, Nachi $S$, Ito $Y$, Marui $T$, Saji $S$, et al. Acinar cell carcinoma arising from an ectopic pancreas. Surg Today. 2007;37:704-7.

7. Ambrosini-Spaltro A, Potì O, De Palma M, Filotico M. Pancreatic-type acinar cell carcinoma of the stomach beneath a focus of pancreatic metaplasia of the gastric mucosa. Hum Pathol. 2009;40:746-9.

8. Kusafuka K, Bando E, Muramatsu K, Ito H, Tanizawa Y, Kawamura T, et al. Pancreatic-type mixed acinar-endocrine carcinoma with alpha-fetoprotein production arising from the stomach: a report of an extremely rare case. Med Mol Morphol. 2009;42:167-74.

9. Coyne JD. Pure pancreatic-type acinar cell carcinoma of the stomach: a case report. Int J Surg Pathol. 2012;20:71-3.

10. Yonenaga $Y$, Kurosawa M, Mise M, Yamagishi M, Higashide S. Pancreatictype acinar cell carcinoma of the stomach included in multiple primary carcinomas. Anticancer Res. 2016:36:2855-64.

11. Kim KM, Kim CY, Hong SM, Jang KY. A primary pure pancreatic-type acinar cell carcinoma of the stomach a case report. Diagn Pathol. 2017;12:10

12. Fujita $Y$, Uesugi $N$, Sugimoto $R$, Eizuka $M$, Matsumoto $T$, Sugai $T$, Gastric mixed neuroendocrine-non-neuroendocrine neoplasm (MiNEN) with pancreatic acinar differentiation: a case report. Diagn Pathol. 2019;14:38.

13. Bell PD, DeRoche TC, Huber AR. Mixed acinar-endocrine carcinoma (MAEC) arising in duodenal pancreatic heterotopia. Case Rep Pathol. 2019. https:// doi.org/10.1155/2019/1713546

14. Moncur JT, Lacy BE, Longnecker DS. Mixed acinar-endocrine carcinoma arising in the ampulla of Vater. Hum Pathol. 2002:33:449-51.

15. Makhlouf HR, Almeida $\mathrm{L}$, Sobin LH. Carcinoma in jejunal pancreatic heterotopia. Arch Pathol Lab Med. 1999;123:707-11.

16. Hervieu V, Lombard-Bohas C, Dumortier J, Boillot O, Scoazec JY. Primary acinar cell carcinoma of the liver. Virchows Arch. 2008;452:337-41.

17. Agaimy A, Kaiser A, Becker K, Bräsen $\mathrm{JH}$, Wünsch $\mathrm{PH}$, Adsay NV, et al. Pancreatic-type acinar cell carcinoma of the liver: a clinicopathologic study of four patients. Mod Pathol. 2011;24:1620-6.

18. WHO Classification of Tumours Editorial Board. WHO classification of Tumours of the digestive system. 4th ed. Lyon: International Agency for Research on Cancer (IARC; 2010.

19. WHO Classification of Tumours Editorial Board. WHO classification of Tumours of endocrine organs. 4th ed. Lyon: International Agency for Research on Cancer (IARC; 2017.

20. La Rosa S, Sessa F, Uccella S. Mixed neuroendocrine-nonneuroendocrine neoplasms (MiNENs): unifying the concept of a heterogeneous Group of Neoplasms. Endocr Pathol. 2016;27:284-311.

21. La Rosa S, Marando A, Sessa F, Capella C. Mixed Adenoneuroendocrine carcinomas (MANECs) of the gastrointestinal tract: an update. Cancers. 2012; 4:11-30.

22. Hosoda W, Sasaki E, Murakami Y, Yamao K, Shimizu Y, Yatabe $Y$. BCL10 as a useful marker for pancreatic acinar cell carcinoma, especially using endoscopic ultrasound cytology specimens. Pathol Int. 2013;63:176-82

23. Rayhan N, Sano T, Qian ZR, Obari AK, Hirokawa M. Histological and immunohistochemical study of composite neuroendocrine-exocrine carcinomas of the stomac. J Med Investig. 2005:52:191-202.

24. Makuuchi R, Terashima M, Kusuhara M, Nakajima T, Serizawa M, Hatakeyama K, et al. Comprehensive analysis of gene mutation and expression profiles in neuroendocrine carcinomas of the stomach. Biomed Res. 2017:38:19-27.

25. Ormarsson OT, Gudmundsdottir I, Mårvik R. Diagnosis and treatment of gastric heterotopic pancreas. World J Surg. 2006:30:1682-9.

26. Chandan VS, Wang W. Pancreatic heterotopia in the gastric antrum. Arch Pathol Lab Med. 2004;128:111-2.

27. Milione M, Maisonneuve P, Pellegrinelli A, Grillo F, Albarello L, Spaggiari P, et al. Ki67 proliferative index of the neuroendocrine component drives MANEC prognosis. Endocr Relat Cancer. 2018;25:583-93.

28. La Rosa S, Adsay V, Albarello L, Asioli S, Casnedi S, Franzi F, et al. Clinicopathologic study of 62 acinar cell carcinomas of the pancreas: insights into the morphology and immunophenotype and search for prognostic markers. Am J Surg Pathol. 2012;36:1782-95. 
29. Wisnoski NC, Townsend CM Jr, Nealon WH, Freeman JL, Riall TS. 672 patients with acinar cell carcinoma of the pancreas: a populationbased comparison to pancreatic adenocarcinoma. Surgery. 2008;144: $141-8$.

30. Kitagami H, Kondo S, Hirano S, Kawakami H, Egawa S, Tanaka M. Acinar cell carcinoma of the pancreas: clinical analysis of 115 patients from pancreatic Cancer registry of Japan pancreas society. Pancreas. 2007;35:42-6.

\section{Publisher's Note}

Springer Nature remains neutral with regard to jurisdictional claims in published maps and institutional affiliations.

Ready to submit your research? Choose BMC and benefit from:

- fast, convenient online submission

- thorough peer review by experienced researchers in your field

- rapid publication on acceptance

- support for research data, including large and complex data types

- gold Open Access which fosters wider collaboration and increased citations

- maximum visibility for your research: over $100 \mathrm{M}$ website views per year

At BMC, research is always in progress.

Learn more biomedcentral.com/submissions 